\title{
Influencias y relaciones de la Doctrina Truman en la configuración del enemigo interno en Colombia
}

\section{Influences and implications of the Truman Doctrine in Shaping Colombia's Internal Enemy \\ Influências e relações da Doutrina Truman \\ na formação do inimigo interno na Colômbia}

Jaime A. Castañeda Hernández

Candidato a Magíster

Universidad Nacional de la Plata

Recibido: 5/4/2016 - Aceptado: 10/7/2016

DOI: http://dx.doi.org/10.15359/tdn a.32-60.5

\section{Resumen}

La cuestión del enemigo interno, aliado de la conspiración comunista internacional en la órbita de América Latina, se aborda en este artículo como la aplicación sistemática de un paquete de medidas desprendidas de la Doctrina Truman y, en su trasfondo, de la inevitable paradoja del drama universal del bien contra el mal, comunismo o capitalismo, civilización o barbarie, en los lenguajes de la posguerra (Guerra Fría). En ese escenario de polaridades de las naciones del Cono Sur y Mesoamérica,

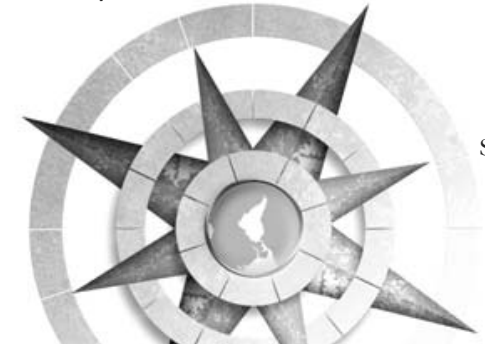

consideradas por Estados Unidos de América como «necesitadas» y dependientes de la protección y salvaguarda de la Nación del Águila Imperial, se analiza cómo fueron implementadas las agencias de inteligencia, como el Departamento Administrativo de Seguridad (DAS) y la Dirección de Inteligencia de la Provincia de Buenos Aires (DIPBA), en Colombia y Argentina. Se expone cómo devino en persecución política, violación de los derechos humanos y agudización de condiciones de vida de los pobladores, quienes, al ser considerados como opositores de los Gobiernos de la época, fueron agredidos, perseguidos y asesinados. De igual forma, se establece una crítica a la Escuela de las Américas y su implementación de tácticas y estrategias contraguerrilleras que, en vez de atenuar «daños» o socializar a la población civil, ha arrojado a lo largo de décadas una estela de sistemáticas violaciones a los derechos humanos. 
Palabras claves: Doctrina Truman, enemigo interno, derechos humanos en América Latina, persecución política, militancia comunista, contraguerrilla

Abstract

The concept of the internal enemy as "the ally of the international communist conspiracy" in Latin America is addressed in this article as the systematic application of a series of measures drawn from the Truman Doctrine and, at its core, the inevitable paradox of the universal war of good vs. evil, communism vs. capitalism, civilization vs. barbarism, in the language of the post-Cold War and the polarity of the nations of the Southern Cone and Mesoamerica, considered by the United States to be in need of the protection and safeguarding of the imperial eagle nation. Within this context, we analyze how intelligence agencies such as the Administrative Department of Security (DAS) and the Secretariat of Intelligence of the Province of Buenos Aires (DIPBA) were implemented in Colombia and Argentina, respectively, giving rise to political persecution, human rights violations, and the deterioration of the living conditions of the people, who were assaulted, persecuted and assassinated for opposing the governments of the time. Likewise, the article harshly criticizes the School of the Americas for its systematic implementation of counter-guerrilla tactics and strategies, which, far from alleviating damages or socializing the civil population, has left a trail of systematic human rights violations throughout the decades.
Keywords: Truman Doctrine, internal enemy, human rights in Latin America, political persecution, Communist militancy, counter-guerrilla

\section{Resumo}

Este artigo aborda a questão do inimigo interno -o aliado da conspiração comunista internacional na órbita da América Latina- como uma aplicação sistemática de um conjunto de medidas resultantes da Doutrina Truman. Em seu fundo, é o resultado do paradoxo inevitável do drama universal do bem contra o mal, o comunismo ou capitalismo, civilização ou barbárie, na linguagem da Guerra Fria. A partir dessas polaridades, as nações do Cone Sul e Mesoamérica foram considerados pelos Estados Unidos como "carente" e dependente da protecção e salvaguarda. $\mathrm{O}$ artigo analisa como foram implementadas as agências de inteligência, tais como o Departamento Administrativo de Segurança (DAS) e a Diretoria de Inteligência da Província de Buenos Aires (DIPBA) na Colômbia e Argentina, respectivamente. Ele discute como tornou-se a perseguição, violação dos direitos humanos e ao agravamento das condições de vida das pessoas, que, sendo considerados como adversários dos governos do tempo político foram atacados, perseguidos e mortos. Da mesma forma se critica a Escola das Américas e sua implementação das táticas e estratégias contra-guerrilha; contudo em vez de atenuar os danos ou socializar a população, deixaram um rastro de violações sistemáticas dos direitos humanos ao longo de décadas.

94 Influencias y relaciones de la Doctrina Truman ...
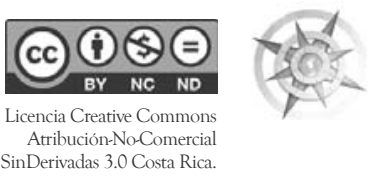
Jaime A. Castañeda-Hernández 
Palavras chave: Doutrina Truman, inimigo interno, direitos humanos na América Latina, perseguição política, militância comunista, contraguerrilla

El presente artículo busca responder cuestiones relacionadas con la Doctrina Truman y cómo sus adaptaciones influyeron en la construcción de un enemigo interno en Colombia. Sumado a lo anterior, se abordan sus reflejos, permanencias y transformaciones en la realidad colombiana y latinoamericana en lo que repetitivamente investigadores e historiadores denominan como la época de la violencia $^{1}$ en principio temporalmente datada a partir de la muerte del dirigente liberal Jorge Eliecer Gaitán, el 9 de abril de 1948, en la ciudad de Bogotá, hasta la firma del acuerdo bipartidista (Frente Nacional) en 1958. Se consideran las matizaciones de las que inicialmente se denominaron guerrillas de autodefensa campesina, guerrillas liberales, las cuales, de acuerdo al perfil de enemigo interno y disidente, se convirtieron luego del acuerdo bipartidista en las guerrillas

1 Gran cantidad de investigadores e historiadores la denominada época de la violencia cifran sus orígenes a partir de la muerte de Jorge Eliecer Gaitán, otros consideran que los aspectos que definen la confrontación durante la década de 1940 tienen antecedentes durante la Guerra de los Mil Días que cierra el siglo XIX, abre el siglo XX y concluye con la pérdida de Panamá. móviles de las Fuerzas Armadas Revolucionarias de Colombia-Ejército del Pueblo (FARC-EP) y el Ejército de Liberación Nacional (ELN).

En ese contexto, este análisis destacará un caso de violencia política acaecido en la entonces Inspección Especial Departamental de Policía Arauca, en la zona cafetera de Colombia, un pequeño caserío de liberales y conservadores que a tesón de imponer su «credo ideológico» se van a las armas el 29 de octubre de 1949 en la localidad de Arauca. Luego de una brutal confrontación entre liberales y conservadores, se encontraron

...cerca de cuarenta muertos. $-\mathrm{Va}$ rias casas incendiadas. $-\mathrm{El}$ ataque inicial se realizó contra las autoridades (...) No menos de quince cadáveres se llevó el Cauca aguas abajo. En una inmensa mancha de sangre se convirtió el gran puente y la autoridad triunfó sobre los perturbadores (Arango, J., 31 de octubre, 1949, p. 1).

A lo anterior se adjunta que el ataque desde los medios oficiales fue atribuido a los liberales; quienes, distinto a los conservadores, perfilaban al enemigo que delineaban los vencedores de la Segunda Guerra Mundial. Entrado el periodo de posguerra, se implementó lo que el mundo conoció como la Guerra Fría, que Hobsbawm divide en distintas etapas, pero que para el periodo

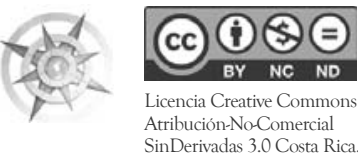

Influencias y relaciones de la Doctrina Truman ... 95

Jaime A. Castañeda Hernández 
que nos convoca responde al nombre de "primera guerra fría» (Hobsbawn, 1994: p. 447), comprendida entre 1947 y 1953. Ello a tenor de que

Hacia 1945 comenzó a perfilarse la estrategia guerrera de la reacción conservadora. Al amparo de la doctrina Truman, que preconizaba el enfrentamiento inevitable con la Unión Soviética. Al finalizar la Segunda Guerra Mundial, comenzó a aplicarse un plan de violencia de baja intensidad en los campos y pueblos. Se trataba de impedir el triunfo electoral de Jorge Eliecer Gaitán, desmovilizar a las masas campesinas, anular la capacidad de resistencia del pueblo y recuperar el control de la tierra para el gran latifundio (Vidales, 1997: p. 3).

La realidad colombiana, en el marco de la confrontación bipartidista, es una expresión en la construcción de la figura de un enemigo frente al orden imperante que aparece como propio, insustituible y permanente. En Colombia el conflicto ha dejado tras de sí innumerables casos de silencio y olvido -impunidad-- aunado a la existencia de abundantes testimonios orales que dan fe de ello. Al respecto, las versiones de quienes no estaban en la oficialidad, deslindados del partido conservador, liberales, y quienes no lo eran, eran señalados de comunistas, ya que como expone Barbero y Godoy (2003) la persecución al comunismo va más allá del Partido Comunista de Colombia para alcanzar al movimiento popular, independientemente de su identificación ideológico-sectaria. Así, cualquier movimiento contestatario al sistema o que pueda representar un desequilibrio del estatus imperante, será calificado de subversivo o comunista.

Para el caso de Colombia, en la primera mitad del siglo XX los afiliados al Partido Liberal serán enmarcados como enemigos del régimen imperante dentro del universo bipolar. Colombia se identifica como escenario de confrontaciones y guerras durante los siglos XIX y XX, en razón de luchas ideológicas, cuando asistió a diversas contiendas armadas e internas. Valga señalar que el país cierra el siglo XIX y abre el XX en guerra: se trata de la denominada Guerra de los Mil Días, cuyo resultado inmediato fue la pérdida de Panamá. Posteriormente, y tras la asunción de posiciones tolerantes, el país asistió a un periodo de relativa calma incluso en el marco de la Primera Guerra Mundial pero el país no fue ajeno a los sucesos de la Segunda Guerra Mundial. En ese orden de ideas, es entendible que

el período más explosivo fue el que medió entre la proclamación formal de la «doctrina Truman» en marzo de 1947: «La política de los Estados Unidos tiene que ser
96 Influencias y relaciones de la Doctrina Truman ... Jaime A. Castañeda-Hernández

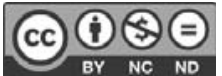

Licencia Creative Commons Atribución-No-Comercial SinDerivadas 3.0 Costa Rica.

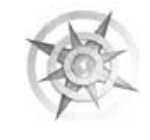


apoyar a los pueblos libres que se resisten a ser subyugados por minorías armadas o por presiones exteriores» (Hobsbawm, 1994: p. 233).

Lo anterior se comprendía en la concepción de la amenaza comunista, por lo cual, de acuerdo con estas consideraciones los Estados Unidos de Norteamérica se veían en el deber de hacer militares latinoamericanos formados bajo sus teorías. La lógica era, en aquellos escenarios de influencia norteamericana, la contención, expresión empleada por el diplomático George Kennan en 1946 en referencia a la URSS y su política exterior.

La política exterior de Estados Unidos contemplaba, entre otras cosas, la estandarización política, económica e ideológica en sus áreas cercanas, zonas circundantes y esferas de influencia. Rápidamente el sur y el centro de América fueron poblados e instruidos en una larga cadena de estrategias militares para llevar a cabo la contención que, en palabras de un tipo de a pie, debe ser vista como la consideración plena de la condición de «un enemigo exterior que amenazase a los Estados Unidos» (Hobsbawm, 1994: p. 238), en tanto se diferenciara de este en sus apreciaciones sobre la vida en sociedad.

En América Latina, como subcontinente o región de América, las incidencias de la política exterior norteamericana trataron de delinearse de la manera siguiente:

Los profesionales de la política y de la diplomacia, cuando no les apremian ni los votos ni la prensa, pueden declarar la guerra o negociar la paz sin experimentar sentimientos de odio hacia el bando enemigo, como los boxeadores que se estrechan la mano antes de comenzar la pelea y van juntos a beber una vez que ha terminado (Hobsbawm, 1994: p. 58).

Diversas regiones en el Cono Sur, como Colombia y Argentina, rápidamente fueron instruidas en las nuevas técnicas de detección del enemigo interno, que debía responder a la figura de un individuo partícipe de la "gran "conspiración comunista mundial" y atea siempre dispuesta a derrocar los dominios de la libertad» (Hobsbawm, 1994: p. 235), a tenor de ello se creó, en 1946, la Escuela de las Américas:

(La SOA) en Panamá, que representó uno de los centros de formación militar más importantes en América Latina, que les permitió a los Estados Unidos entrenar en técnicas de combate, tácticas de comando, inteligencia militar, contrainteligencia, guerra revolucionaria, manejo de fuentes entre otros y formar ideológicamente un gran número de militares de esta región (Ahumada, 2007: p. 27).

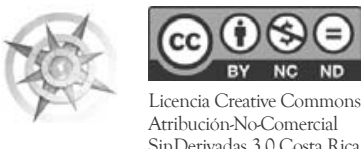

Influencias y relaciones de la Doctrina Truman ... 97 Jaime A. Castañeda Hernández 
De tal manera se establecieron centrales de inteligencia; para el caso colombiano fue creado el Departamento Administrativo de Seguridad (DAS), «a cuyos propósitos se agregan entre otros la vigilancia de los "revoltosos de corte liberal y comunista" " (Castañeda, 2011: p. 3) posterior a los hechos violentos protagonizados por los simpatizantes de Gaitán «y la furia desencadenada de estos tras la muerte del llamado Caudillo del Pueblo» ${ }^{2}$ (Castañeda, p. 3) en otra parte no muy distante de Colombia, en Argentina, vio la luz la extinta DIPBA [Dirección de Inteligencia de la Provincia de Buenos Aires], creada en agosto de 1956 prestando sus servicios hasta el año 1998. No obstante sus actividades se remontan a periodos anteriores. En América Latina, tanto en Colombia como en Argentina, la persecución política e ideológica a los ciudadanos por parte del DAS o la DIPBA, respectivamente, no sólo ocurre desde la dictadura sino en periodos que alcanzan la década de 1930 y la persecución a los anarquistas, situación que se evidencia en el contenido de los archivos que reposan en la Comisión por la Memoria (Castañeda, 2011):

2 En la época en mención los pobladores de Colombia llamaron afectuosamente a Gaitán El Caudillo del Pueblo. Suele reconocérsele también la envestidura de Jefe Único del Partido Liberal, o sencillamente El Jefe.
La DIPBA, creada en 1956, y el DAS, creado tres años antes, no guardan diferencias abismales, salvo su ubicación geográfica, ya que mientras la primera se encargaba de perseguir peronistas y agentes no afectos al Gobierno argentino, el DAS se ocupó de ubicar y perseguir a gaitanistas, liberales, comunistas, socialistas y guerrilleros. (2011: p. 3).

Empero, ¿era realmente una amenaza la presencia de comunistas en América Latina para implementar lo que sobrevino después de arraigado el temor de Estados Unidos, en cuanto a la amenaza del comunismo en América Latina, al punto de comulgar con las diferentes dictaduras militares en el Cono Sur, desde Venezuela hasta Argentina? En relación con ello, las apreciaciones de Hobsbawm señalan que

Desde cualquier punto de vista racional, la URSS no representaba ninguna amenaza inmediata para quienes se encontrasen fuera del ámbito de ocupación de las fuerzas del ejército rojo. Después de la guerra, se encontraba en ruinas, desangrada y exhausta, con una economía civil hecha trizas y un gobierno que desconfiaba de una población gran parte de la cual, fuera de Rusia, había mostrado una clara y comprensible falta de adhesión al régimen (Hobsbawn, 1994: p. 236).

Pareciera necesario reseñar que durante la vigencia de la Primera Guerra Fría

98 Influencias y relaciones de la Doctrina Truman ...

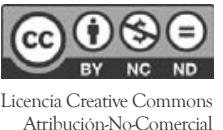
Jaime A. Castañeda-Hernández 
tuvieron lugar en Colombia hechos que reflejan las condiciones reinantes desde los más altos niveles, incluso en Norteamérica. Cabe tener en cuenta que al traste de las declaraciones del presidente Truman sobre la amenaza comunista, en Colombia, en un pequeño poblado de afrodescendientes obreros liberales y conservadores, las implicaciones del enfrentamiento URSS-USA se manifestaron en batallas campales donde los hombres, «luchando como tigres y hasta heroicamente» (Arango, 1949: p.7), ofrecieron su vida con decidido ahínco, fuera por la defensa, fuera por el caso del ataque, por su condición de liberales frente al agresor en el poder: el partido conservador.

En la memoria oficial del Departamento de Caldas, los hechos acaecidos en Arauca el 29 de octubre de 1949 se desprenden de lo afirmado por el diario La Patria (en lo sucesivo LP), al haber referido, de acuerdo con lo dicho por la clase política de la época, que

El gobierno de Caldas puede afirmar, de acuerdo con los datos que tiene en su poder, que en Arauca hubo un asalto preparado y dirigido por el liberalismo en connivencia con elementos comunistas, todo lo cual correspondía a un plan tenebroso cuyas mayores consecuencias fueron evitadas por la acción de las autoridades civiles y militares (Gobernación de Caldas, 1949: p. 5).
El discurso dominante, de acuerdo con Hobsbawm (1994) alude al enemigo, en el drama moral universal que enfrenta al bien con el mal; la URSS versus los Estados Unidos de Norteamérica, socialismo o barbarie, capitalismo o comunismo, o en fin las dos tendencias dominantes balanceadas siempre a la saga y a la espera de la más sensible acción del oponente, siempre al filo de la guerra total.

En el caso de Arauca, el enemigo fue perfilado dentro de aquellos que se reconocían como liberales (obreros, comerciantes campesinos). Los sobrevivientes recuerdan que en el marco de los acontecimientos, en su huida, mientras pedían ayuda al Ejército, obtenían como respuesta:

Yo si les voy a dar un consejo para que se salven, pidan traslado, pidan traslado para otra sección y donde lleguen, digan que son conservadores, digan si les preguntan: Nosotros somos conservadores, ¿Por qué? Porque la orden del gobierno es matar liberales (Montoya, 2008: p. 16).

Para la época, según la Inspección de Policía, Arauca no superaba los 3000 habitantes, no obstante la concentración de su población durante los fines de semana lo hacían un importante centro de comercio. A su vez contaba con distintas vías hacia Medellín y la capital de Caldas: Manizales, y con el

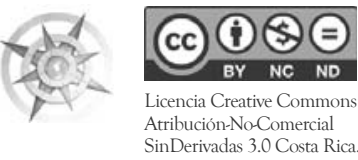

Influencias y relaciones de la Doctrina Truman ... 99 Jaime A. Castañeda Hernández 
servicio de Tren del Pacífico que conectaba a Medellín con el principal puerto de Colombia sobre el Pacífico: Buenaventura. También debe agregarse el flamante aeropuerto internacional (hoy en día fuera de servicio).

Los informes del diario LP dieron cuenta de los acontecimientos violentos en Arauca entre liberales y conservadores, el incendio del pueblo y las decenas de muertos que en su mayoría fueron arrojados al río Cauca. Ahora bien, en otros informes de LP se hace referencia a la Inspección Especial de Policía Arauca como «caserío tropical» y la ya conocida denominación, de acuerdo a la construcción del enemigo del régimen como amenazantes «focos de agitación comunista - liberal permanentes» (Arango, 1949: p. 6). Con lo anterior se establecen lugares de concentración del enemigo interno, quien a tenor de ser o no ser liberal era objeto de la persecución, desaparición y muerte; no obstante quizá Colombia en su largo camino de construcciones y deconstrucciones de enemigos internos sea solo el receptáculo -todavíade las inspiraciones norteamericanas, por cuanto se refiere a su seguridad interna y el temor a lo novedoso, no tradicional, plural, liberal y que amenaza el modelo imperante.

El caserío de Arauca no se distancia de esas realidades de posguerra, ya no a razón de la política internacional de
Washington, sino quizá a causa de las construcciones y necesidades de sostener un aparato represivo del cual no se librarán quienes no entren a tono con la oficialidad. Es decir, el enemigo:

Está integrado no solamente por quienes toman las armas y permanecen en las áreas de combate, sino por los simpatizantes, los encubridores y los auxiliadores. Todos deben ser objeto de estudio dentro de los planes que se adopten, y lo que es más importante, materia de trabajo para la inteligencia militar (Ahumada, 2007: p. 27).

En el marco que comprende un amplio número de "perfiles sospechosos», a las fuerzas armadas colombianas formadas en "escuela de golpes» (Ahumada, 2007: p. 28), consideradas en nuestros días «un dinosaurio de la Guerra fría debido a los múltiples casos denunciados sobre situaciones de tortura, violación de los derechos humanos, asesinatos y desaparecidos» (2007: p.28), les fue fácil caracterizar a los enemigos de la República de Colombia. En ese orden de ideas:

Dentro de las diferentes manifestaciones de la subversión la fuerza pública presenta a las guerrillas como una de las expresiones del enemigo interno en Colombia, a las cuales caracterizan como una organización armada al margen de la ley y agente generador de violencia (p. 28).
100 Influencias y relaciones de la Doctrina Truman ... Jaime A. Castañeda-Hernández

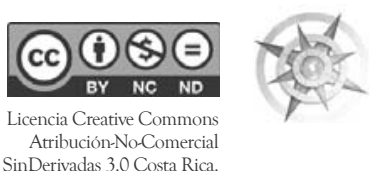


Sin embargo, aquellos que en principio no eran guerrilleros -como los liberales en Arauca y en Caldas en 1949 y los grupos y grupúsculos que se defendían de la Policía y del Ejército al servicio del Gobierno conservador- finalmente fueron alineados dentro del perfil de "comunistas y/o guerrilleros», a sazón de ello las Fuerzas Militares de Colombia estereotiparon como subversivos a aquellos que sobrevivieron a los ataques entre 1945 y 1957 , cuando en realidad no lo eran. De modo semejante las Fuerzas Militares de Colombia y Suramérica siguieron a pie juntillas las "orientaciones y enseñanzas» obtenidas en la Escuela de las Américas, según un conocido manual de la época empleado por las FFMM de Colombia. Además del conocido enemigo comunista, de lo que se trataba era del combatiente:

El guerrillero es un hombre que lucha, que emplea medios no convencionales, cuyas características principales son: «la iniciativa, movilidad, flexibilidad, versatilidad y la capacidad para desempeñar correctamente entre la población civil no comprometida». Los objetivos que persigue son: «la toma del poder (...)» (Fuerzas Militares de Colombia, 1977: p. 13).

La identificación del enemigo no es más que la equivocada concepción de considerar la vOz quien no está conmigo está contra mí, vieja enseñanza de los vencedores de la guerra, para los cuales en esta parte del hemisferio se encontraban sus enemigos potenciales, el enemigo al cual se debía reconocer, ubicar y destruir, es decir, aquel que se prestaba a la conspiración comunista. El destinatario de la represión del Estado, de la mano de hierro de las dictaduras o bien de las enseñanzas que recibían los militares condecorados en sus respectivos países a su paso por la Escuela de las Américas bien pudiera ser Argentina, Colombia, o en su defecto Arauca.

En consecuencia, apegados a la buena fe hemos de creer que no fue el Gobierno colombiano en primera persona quien propició la creación de un enemigo que se hizo real a partir de 1960 y la transformación de las asociaciones de autodefensa de corte liberal en las guerrillas móviles comunistas de las FARC-EP, así como el ELN. A su vez, apegados a la buena fe de los gobernantes y dirigentes políticos hemos de confiar de nuevo en que no fueron precisamente los Estados Unidos quienes plagaron de armas y terrorismo de Estado el Cono Sur; quisiéramos, desde nuestra buena fe, creer que

No fue el gobierno de los Estados Unidos quien inició el sórdido e irracional frenesí de la caza de brujas anticomunista, sino demagogos por lo demás insignificantes -algunos, como el tristemente famoso senador Joseph McCarthy,

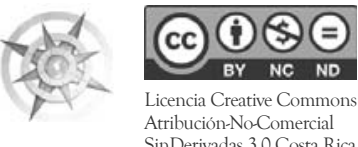

Influencias y relaciones de la Doctrina Truman ... 101

Jaime A. Castañeda Hernández 
ni siquiera especialmente anticomunistas- que descubrieron el potencial político de la denuncia a gran escala del enemigo interior (Hobsbawm, 1994: p. 239).

De lo que se desprende el famoso verbo macartizar, que quiere decir 'señalar', 'estigmatizar' o cualquiera de sus acepciones como siniestro recuerdo, memorias de lo que ha sido para Latinoamérica un largo periodo que finalizó el siglo pasado. Aún para el caso de Colombia el período no cierra del todo, pues si bien en principio se trató de acabar con la guerrilla, tal situación no resulta efectivamente cierta y la prolongación de las calamidades y desventuras de la población colombiana aún guardan rezagos de aquello que recomienda, reiteradamente, Estados Unidos, llámese Doctrina Truman, teoría de la Seguridad Nacional, las enseñanzas impartidas en la Escuela de Las Américas o el Plan Colombia, o bien las construcciones de enemigos que terminaron cobrando forma y asumiendo lo que se les señalaba como es el caso de las FARC-EP, y no en la misma medida el ELN.

El frenesí y la incertidumbre de la guerra inmediata fueron no solamente vividos en las entrañas de Estados Unidos, sino también en los intestinos mismos de las naciones latinoamericanas que, desde Venezuela hasta Argentina, asistieron a periodos de violencia, terrorismo de Estado, persecución política, genocidio torturas, con saldos de decenas de miles de desparecidos, como lo ilustra el caso argentino durante la dictadura militar de 1976-1983.

En la instrumentalización de estos planes de contención de la conspiración comunista, Estados Unidos planeó, financió y ejecutó acciones que violaban, a todas luces, los derechos humanos. Empero, en el caso argentino por ejemplo -por no mencionar a Chile- las acciones y agresiones llegaron, si no a buen término, a su final durante el siglo pasado. El conflicto se asumió con frontalidad y memoria a modo de hacer justicia. Mientras que en Colombia, para algunos el país va camino a sesenta años de vigencia de un conflicto ininterrumpido aunque negado. Al respecto pueden analizarse las declaraciones del ex-presidente Uribe sobre el conflicto social y armado en Colombia durante su mandato. Para otros -como en el caso del autor de este artículo- la guerra, el conflicto y el tormentoso tema de la confrontación armada e ideológica en Colombia se remontan a épocas anteriores. Hay quienes incluso están agotados de escuchar que el periodo de violencia o por lo menos del conflicto armado se remonta escasamente a la muerte de Jorge Eliecer Gaitán.
102 Influencias y relaciones de la Doctrina Truman ... Jaime A. Castañeda-Hernández

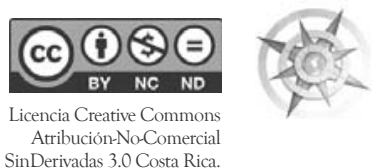




\section{Conclusiones}

Posterior a la segunda guerra mundial el mundo vio como entre dos bloques, temerosos, unos y otros se diputaban abstracta e hipotéticamente sus adeptos, so pena de que quienes no estuvieran dentro de sus líneas -en especial la de los Estados Unidos- serían castigados criminalizados, señalados, macartizados o bien estereotipados como un enemigo del régimen imperante Aquellos individuos que fuesen considerados como subversivos, guerrilleros, comunistas, colaboradores, auxiliadores o milicianos (este último en el caso de Colombia), debían ser controlados; todo ello a tenor de los planes sistemáticos diseñados por la Nación del Águila Imperial.

Las construcciones del enemigo, así como la creación de agencias que desempeñaban labores de "inteligencia" persecución política e ideológica a los ciudadanos, sospechosos según el régimen, de una posible participación en la "conspiración comunista", obligaban a tomar bando.

En ese marco de acontecimientos, en una región distante de Colombia, en Arauca de Caldas, pudo verse aquel enemigo de corte liberal comunista, asediado, creado e imaginado al punto de llegar a cambiarle al caserío de Arauca su toponimia de «pueblo tropical» por el de «bandoleros liberales comunistas». Así lo señaló el diario local La Prensa, sin embargo, otras voces manifiestan lo contrario. Los relatos que se entrecruzan entre liberales y conservadores, hombres y mujeres de carne y hueso que hicieron historia, acontecimientos traumáticos que sin ahondar en el asunto de la responsabilidad y la claridad de los hechos, permanecen vivos en la memoria.

Estos fueron hechos que vistos desde la óptica de "un sujeto que piensa», un poco más allá del anecdotismo, constituyen un verdadero problema, en tanto que las versiones de medios oficiales así como las de ciudadanos comunes y la tradición oral, no son consecuentes en términos de «verdad histórica», cuando se hace hincapié en ellas, sea desde la óptica que ofrece el estudio de la memoria visual o la historia oral, local o regional en Caldas, departamento cafetero de Colombia.

\section{Referencias}

Ahumada, M. (2007). El enemigo interno en Colombia. Ecuador: Ediciones Abya Yala.

Arango, J. (31 de octubre de 1949). Feroz asalto al corregimiento de Arauca realizaron los bandoleros. La Patria pp. 1-7

Barbero, H. y Godoy, G. (Junio de 2003). La configuración del enemigo interno como parte del esquema represivo argentino. Décadas de 1950-1960. En Cuadernos de Trabajo, N. o 55. pp. 1-68

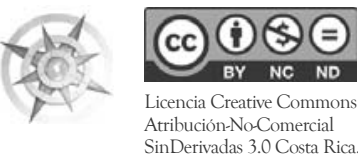

Influencias y relaciones de la Doctrina Truman ... 103

Jaime A. Castañeda Hernández 
Castañeda, J. (Noviembre, 2011). Relatoría de la conferencia «Comisión Provincial de la Memoria presentación de actividades» dictada por Sandra Raggio y Laura Lenci. Aletheia, 2(3) pp. 1-5

Gobernación de Caldas (15 de noviembre de 1949). Declaración del gobierno de Caldas sobre los hechos de sangre de Arauca. La Patria.
Hobsbawm, E. (1994). Historia del siglo XX. Buenos Aires: Crítica Grijalbo Mondadori.

Fuerzas Militares de Colombia. (1999). Reglamento de guerrillas y contraguerrillas urbanas. Colombia: Editorial Fuerzas Militares de Colombia.

Vidales, C. (1997). La violencia en Colombia (III). La gran violencia. Recuperado de http://vidales.tripod.com/VIOLEN03.HTM

104 Influencias y relaciones de la Doctrina Truman ... 